\title{
Predicting the Number of GHB-Related Toxicologic Admissions Using Google Trends Data
}

\author{
Máté Kapitány-Fövény ${ }^{1,2} \cdot$ Tamás Ferenci $^{3,4} \cdot$ Zsolt Demetrovics $^{5,6} \cdot$ Mihály Sulyok $^{7}$
}

Accepted: 3 November 2021

(c) The Author(s) 2021

\begin{abstract}
In the era of novel psychoactive substances (NPS), the internet became a relevant source of information and purchase for those who consume psychoactive drugs. Parallelly, a growing body of research aim to utilize web search metrics (most commonly by relying on Google Trends data) in the prediction of substance use-related trends, including epidemiological forecasting. The main goal of the current study was to assess the utility of web search queries in the prediction of Gamma-hydroxybutyrate (GHB)-related toxicologic admissions in Hungary by performing additive decomposition of time series to identify trend and seasonal components. Monthly data identified GHB-related search volume representing nationwide web interest towards this substance was found to be a significant covariate of admission rates; the seasonal component showed two peaks in the admission rates: one in December/January and another one in May, whereas more admissions on the weekends were observed as compared to weekday data in Hungary. By taking into account the subtle effect sizes of this study, these results suggest that Google Trends data may be useful in forecasting toxicologic admissions on a monthly level, yet a number of limitations should be considered when interpreting these associations. Web search metrics can therefore be used for early warning purposes in the field of toxicology as well. An external validation approach is also suggested by the authors.
\end{abstract}

Keyword GHB; Toxicologic admission; Google Trends data; Forecasting

Máté Kapitány-Fövény

m.gabrilovics@gmail.com

1 Faculty of Health Sciences, Semmelweis University, 1088 Budapest Vas u. 17., Budapest, Hungary

2 National Institute of Mental Health, Neurology and Neurosurgery - Nyíró Gyula Hospital, Budapest, Hungary

3 John von Neumann Faculty of Informatics, Physiological Controls Research Center, Óbuda University, Budapest, Hungary

4 Department of Statistics, Corvinus University of Budapest, Budapest, Hungary

5 Centre of Excellence in Responsible Gaming, University of Gibraltar, Gibraltar, Gibraltar

6 Institute of Psychology, Eötvös Loránd University, Budapest, Hungary

7 Department of Pathology, Institute of Pathology and Neuropathology, University Hospital Tübingen, Tübingen, Germany 
In the past decades, with growing access to the internet, people who use psychoactive substances and drug traffickers started to gather information about various novel drugs (novel psychoactive substances or NPS) via web fora-e.g., Erowid, Dancesafe, Bluelight, and Lycaeum (Smith \& Garlich, 2013)—while online drug purchase, including the supply of illicit online pharmacies (Mackey and Nayyar, 2016), also became a relevant public concern, as illegal entities often sell prescription drugs without proper medical control (Fincham, 2021). Easy availability provided by online sourcing is one of the main reasons of NPS' maintained popularity (Miliano et al., 2018; Van Hout \& Hearne, 2017), but cryptomarkets are considered to increase the use of not only NPS but illicit and legal drugs in general, including the elevated consumption of cannabis, Ecstasy, several psychedelic drugs, and prescription medications (Aldridge et al., 2018). E-psychonauts (i.e., informed users of mainly NPS within online drug fora communities) (Orsolini et al., 2015) and social media users also tend to post about their drug experiences (e.g., Cavazos-Rehg et al., 2016; Kalyanam et al., 2017), creating an immense body of online information about the current drug scene.

Web search data provided by Google Trends can be useful means of forecasting behavioral trends, including substance use habits and related adverse outcomes. Monitoring of these internet search metrics relies on the premise that people who use psychoactive substances are likely to search the internet in order to gain relevant information about the availability or potential risks of psychoactive drugs. The epidemiology of substance use and its consequences (e.g., intoxication) has been accordingly studied in light of Google Trends data. Bright et al. (2013) assessed the association between synthetic cannabinoid (SC) legislation, SC's media coverage, the traffic of SC-related web search terms, and the incidence of SC use, emphasizing the impact of media stories on the creation of a "moral panic," leading to the ban of SC agonists. Similarly, Kapitány-Fövény and Demetrovics (2017) found that the connection between mephedrone-related web search rates and the legislative status of this NPS was mediated by its online media coverage. Gamma et al. (2016) pointed out that Google search activity might be a potential predictor of methamphetamine-related crimes. Steppan et al. (2013) outlined that Google search volume indices serve only as a weak indicator of cannabis use prevalences; on the other hand, high correlations between Google Trends data and prevalence rates from the Monitoring the Future Study (exploring substance use patterns among adolescents) for five distinct NPSs (including synthetic cannabinoids and bath salts) were demonstrated by Perdue et al. (2018). A recent study (Batistic et al., 2021) indicated that out of three potential data sources regarding the occurrence of NPS-related novel information-(1) Google Trends, (2) Drug forum data, and (3) UNODC reports-NPS data first appear on Google Trends, with temporal comparisons suggesting that the order of occurrence of NPS data align consistently for most NPS classes, implying that Google Trends data provide a valid source to monitor NPS presence on the drug market. Ghosh et al. (2021) further demonstrated how year- and state-wise relative search volumes (RSV) for the search terms "naloxone" and "drug overdose" positively correlate with actual drug overdose mortality rates published by the National Center for Health Statistics (USA). As regards the utility of web search query rates in the field of toxicology, so far only one study (Yin \& Ho, 2012) tested internet search query data as a surveillance method for a toxicological outbreak of "bath salts" (synthetic cathinones), using Google Insights for Search (GIS). To the best of our knowledge, no former studies have attempted to explore the predictive potential of web search metrics in forecasting GHB-related intoxication rates.

Our primary research question addressed the utility of web search queries in predicting the rates of toxicological cases. This study therefore aimed to assess whether the 
monitoring of specific drug-related web searches might be a beneficial tool in predicting toxicologic admissions related to the use of the same substance. GHB (Gamma-hydroxybutyrate) was selected as a test agent for such purposes for the following reasons: GHB is a popular club drug consumed by a considerable proportion of certain subpopulatione.g., club goers or men who have sex with men (e.g., Hammoud et al., 2018) —and as a potent depressant, it has the ability to induce various adverse effects, including respiratory depression, hypoventilation, bradycardia, absence of gag reflex, acidosis, or mild hypothermia (e.g., Couper et al., 2004; Madah-Amiri et al., 2017). At or around the time of our toxicological data collection (2009-2013), based on the results of two nationally representative studies conducted concurrently every 4 years (the ESPAD and the OLAAP studies), GHB consumption was characterized by increasing prevalence rates in Hungary, both among adolescents (Elekes, 2012) and the young adult population (Paksi et al., 2018), with lifetime prevalences of $2.5 \%$ and $1.5 \%$ identified, respectively. The Hungarian ESPAD study observed a 1.9\% lifetime prevalence increase of GHB use between 2007 and 2011 among adolescents (Elekes, 2012). Additionally, as regards GHB-induced intoxication rates, according to the annual reports of the Hungarian National Institute of Chemical Safety, GHB was associated with the third (in 2011) and fourth (in 2013) highest rates of intoxication cases among the identified psychoactive substances (Országos Kémiai Biztonsági Intézet, 2012, 2014). Furthermore, as GHB is widely available via the internet (e.g., Kapoor et al., 2013) and purchased online by a heterogeneous rate of those who intentionally consume this substance, from 14 (Barker et al., 2007) to 46\% (Stein et al., 2011), it also makes it possible to verify our assumption as follows: out of those who search for GHB on the internet, some will also purchase and consume this drug, may face intoxication, and thus will be admitted to a toxicology ward. As searching precedes buying, consuming, and admission in time, this train of thought forms the basis of the hypothesis that web search queries may be able to predict toxicologic admissions and that Google Trends might be a useful tool for early warning purposes within the field of toxicology as well.

\section{Materials and Methods}

\section{Data}

With regard to GHB-related toxicologic admission numbers, we analyzed a dataset of a previous study (Kapitány-Fövény et al., 2017). This dataset was established on the basis of the medical reports of the Clinical Toxicology Ward of Péterfy Sándor Street Hospital Clinic and Casualty Centre, the biggest toxicology center in Hungary, with approximately eleven thousand patients admitted here each year. Importantly, this center is the main treatment site in the capital as well as its urban agglomeration. Moreover, approximately $32-40 \%$ of the center's toxicological referrals come from rural areas (e.g., Országos Kémiai Biztonsági Intézet, 2012), indicating the center's nationwide treatment responsibilities. Every patient with proven GHB consumption was added to the database, and their medical reports between 14th of September 2009 and the 13th of June 2013 were reviewed. Considering the applied analytical procedure in the identification of GHB use, patients' serum and/or urine samples were analyzed, and working solutions were prepared from the GHB stock solution (1000 mg/L in methanol) (for detailed sample characteristics and analytical methods, see Kapitány-Fövény et al. (2017)). As many patients were treated several times at the same site, patient numbers and case numbers were separately registered. 
For this analysis, we used only case numbers to observe monthly admission frequencies between the given dates described above, as Google Trends search queries-similarly to recurrent toxicological cases induced by the same patient-may have derived from multiple searches from a given individual. Our further aim was to include the highest possible number of observations in order to increase the effect sizes. Altogether 131 GHB intoxication cases were added to our dataset with the corresponding dates. These 131 cases were derived from 111 patients.

GHB-related web search query rates within the same time interval (September 2009 to June 2013) were obtained from using Google Trends data (GTD) for Hungary, in order to compare toxicological data and web searches within the exact same time frame. The GTD data were therefore selected to match the treatment dates of the previously recorded toxicological cases. Considering further applied search filters, a nationwide location was selected (i.e., anywhere from Hungary). The selection of search inputs was done in line with the work of Nuti et al. (2014). Google Trends reports search volumes for particular search terms as a portion of the total search numbers for a specific area. Data provided by Google Trends therefore represent an adjusted value for overall search volume. The values are integers of the relative weekly search "volume," where 100 represent the highest search activity. Our main unit of analysis was RSV scaled to the highest proportion week and correlated with monthly toxicological admission data. Two separate search terms were used: (1) "GHB" (henceforth referred to as GHB-related search volume), (2) "Gina drog" (the Hungarian street name for GHB, henceforth referred to as Gina-related search volume). These search inputs represented the most commonly used terms for this substance in Hungary. Monthly GHB and Gina-related search rates were applied as the main units of analysis. As regards Google Trends' query category, we selected the "all categories" option.

\section{Statistics}

Additive decomposition of time series was performed to identify trend and seasonal components. Differences between daily admission rates per weekday were assessed with the Dunn-test with Holm correction to counteract problems with multiple testing. A contemporaneous correlation between the Google Trends data and the monthly admission numbers was assessed with Kendall- $\tau$ correlation. Kendall- $\tau$ cross-correlation analysis was also performed between monthly GTD values and monthly admission rates.

A generalized linear model with Poisson regression was fitted using monthly admission numbers as the dependent and GHB-related search volume and Gina-related search volume (contemporaneous and lagged with 1, 2, and 3 months) as independent covariates. As such, besides monthly comparisons between RSV and toxicological admission rates, we established models to explore how temporal changes in RSV values may explain the absolute admission numbers. Lagged monthly admission numbers (up to 3 months) were also added to deal with possible autocorrelation. Residual diagnostics were performed, and no interactions were added to the model. All statistical analyses were performed in $\mathrm{R}$ version 4.0.2 (R Core Team, 2020). Visualization of non-linear relationships was done by using LOESS smoothers (locally estimated Scatterplot Smoothing), a type a local polynomial regression (Fox \& Weisberg, 2018) with or without 95\% confidence intervals. The analysis and the dataset are available online at https://github.com/msulyok/GHBGoogleTrends and detailed in the Supplementary material. 


\section{Results}

\section{Seasonal and Temporal Trends}

The median number of monthly GHB-related admission was 2 (mean 2.9, IQR: 1-4, min-max: 0-13). The median daily admission number was 0 (mean 0.298, IQR: 0, min-max: 0-5). Additive time series decomposition did not reveal any relevant increase or decrease in the trend component of the admission numbers. The seasonal component showed two peaks in the admission rates: one in December/January and another peak in May. This was consistent in all 4 years; when we eliminated the white noise component and the trend component from the time series, the seasonal component showed the aforementioned results.

After comparing all weekdays and weekends with each other in a pairwise fashion, we found that there were more admissions on the weekends, on Saturday and Sunday significantly more than on Thursdays ( $p=0.0188$ and 0.0023 , respectively), and on Sundays more than on Wednesdays $(p=0.0175)$.

The GHB-related Google search volume showed a significant contemporaneous correlation $(\tau=0.2239 ;-0.004-0.452 ; p$-value $=0.03959)$ with the reported monthly case numbers. The correlation with Gina-related Google search volume was not significant $(\tau=0.1408 ; 95 \%$ CI: $-0.063-0.345 ; p$-value $=0.2181)($ Fig. 1$)$.

Cross-correlation analysis revealed the highest correlation at lag 9 (9 months later admission numbers) with GHB-related search volume $(\tau=0.299)$ and at lag 5 (5 months later admission numbers) with Gina-related search volume $(\tau=0.358)$.

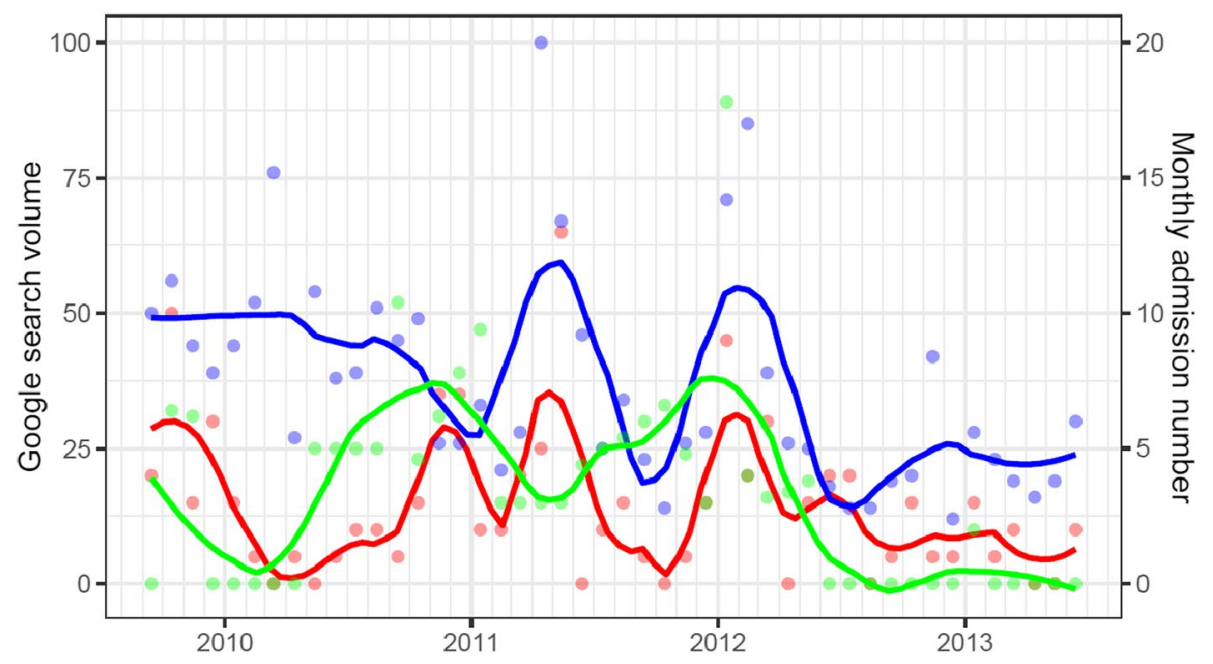

Fig. 1 Google search volumes and monthly admission numbers with LOESS smoothers. Red line and dots, admission numbers; blue line and dots, GHB-related search volumes; green line and dots, Gina-related search volumes 


\section{Predictive Value of Web Search Volumes}

In the fitted model (AIC: 186.31), significant predictors were the GHB-related search volume (lagged with 1 and with 2 months) and the Gina-related search volume (lagged with 2 months). Adding autoregressive components was not significant. Predicted hospital admission numbers are presented in Fig. 2.

Regression coefficients of the model are shown in Table 1; further model diagnostics are available in the Supplementary material. Table 1 thus presents the effect sizes of the covariates (e.g., Google search volumes) on the outcome variable (admission numbers), reflecting on how much change happens in the admission numbers if a change occurs in the covariates.

\section{Discussion}

Online distribution of psychoactive substances is a further expanding phenomenon of the contemporary drug scene. According to the findings of Miliano and colleagues (2018), websites appearing on either the "surface" or the "deep" web are still active despite being constantly shut down by government agencies. These sites' user-friendly marketing strategies, such as reduced prices for first purchase, proposals of drug consumption equipment (e.g., vaporizers), holiday sales, or guaranteed secure payment (Miliano et al., 2018), make online sourcing a more preferable way of purchase than face-to-face drug trafficking. Therefore, it is of heightened relevance to utilize data created by the online drug scenario

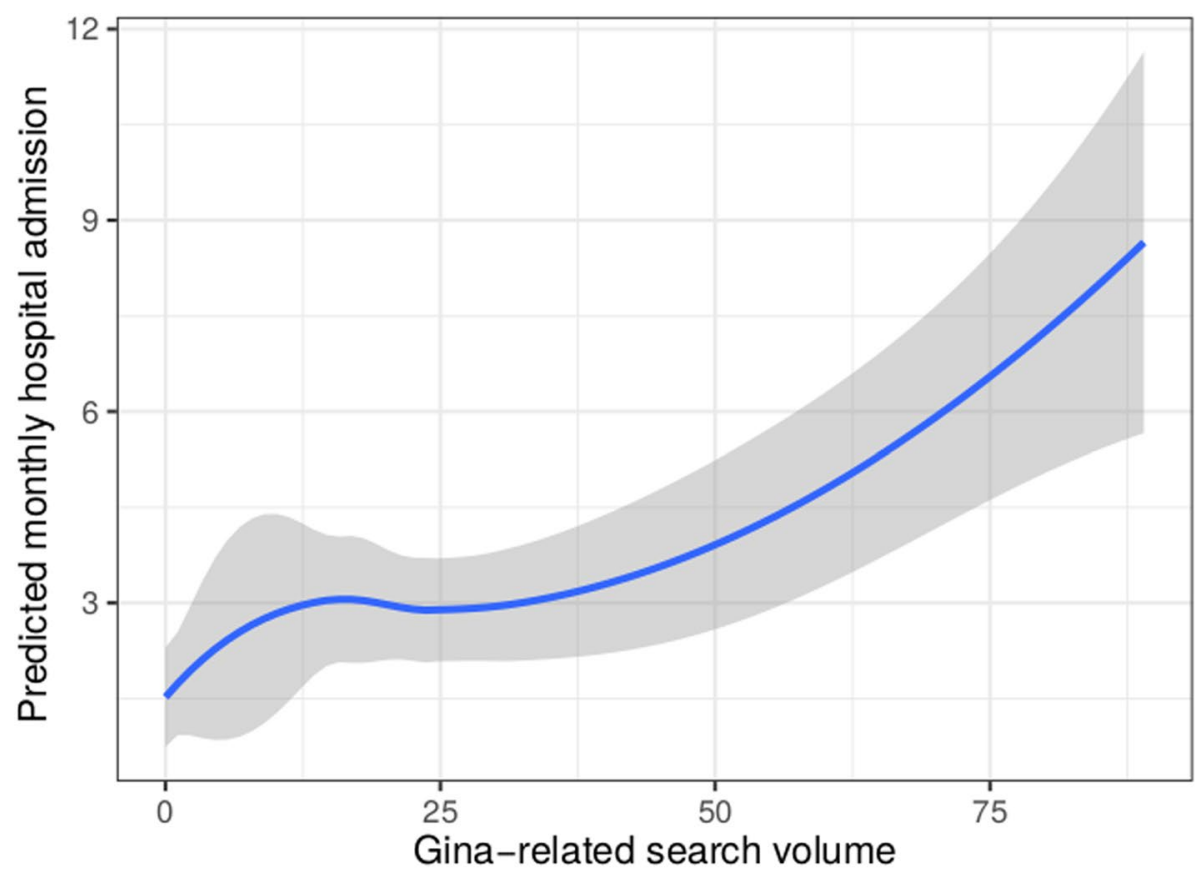

Fig. 2 Predicted hospital admission numbers as a response to GHB-related search volume 
Table 1 Regression coefficients for the fitted model to estimate monthly admission rates

\begin{tabular}{lllll}
\hline Coefficients & $\begin{array}{l}\text { Incidence rate } \\
\text { ratio (IRR) }\end{array}$ & $\begin{array}{l}\text { 95\% CI } \\
\text { Lower IRR }\end{array}$ & $\begin{array}{l}\text { 95\% CI } \\
\text { Upper IRR }\end{array}$ & $p$-value \\
\hline Intercept & 1.190 & 0.582 & 2.304 & 0.618 \\
GHB-related search volume & 1.009 & 0.997 & 1.019 & 0.139 \\
Gina-related search volume & 1.008 & 0.998 & 1.020 & 0.09 \\
GHB-related search volume 1-month lag & 1.010 & 1.001 & 1.024 & 0.023 \\
Gina-related search volume 1-month lag & 0.994 & 0.981 & 1.004 & 0.210 \\
GHB-related search volume 2-month lag & 0.979 & 0.962 & 0.992 & 0.004 \\
Gina-related search volume 2-month lag & 1.023 & 1.008 & 1.033 & 0.002 \\
GHB-related search volume 3-month lag & 1.003 & 0.989 & 1.015 & 0.753 \\
Gina-related search volume 3-month lag & 0.999 & 0.984 & 1.018 & 0.85 \\
Autoregressive order-lag 1 & 1.055 & 0.951 & 1.160 & 0.312 \\
Autoregressive order-lag 2 & 1.009 & 0.916 & 1.088 & 0.99 \\
Autoregressive order-lag 3 & 1.012 & 0.934 & 1.102 & 0.680 \\
\hline
\end{tabular}

Significant coefficients are boldfaced

in different areas within epidemiology, including the monitoring of trends in emergency department visits.

Our results suggest that GTD may be interpreted as a significant covariate in predicting toxicologic admissions on a monthly level. Nevertheless, the effect size was subtle. Thus, the direct clinical relevance of this finding remains rather questionable. The most likely explanation for these small effect sizes is that further unidentified factors (e.g., the curiosity of a potential user, the concern of a relative, or a journalist collecting materials for an article about GHB) (Gamma et al., 2016) may probably play a similarly relevant role in the variability of RSV data. Related to this question, the aforementioned train of thought that web searches precede GHB purchase is not necessarily a sound reasoning, as the patients or relatives of intoxicated patients might as well search for the attributes of GHB shortly after the occurrence of the intoxication. These search motives were unexplored due to the fact that we analyzed routinely collected clinical data with predefined variables.

Comparing our findings with those of Yin and Ho (2012), strong correlations were observed in both studies regarding the possible connection between poison center exposures and web search volumes on a monthly basis. As Mainous and colleagues described (2009), mean delivery time in case of online vendors selling drugs without prescription may take up to 8 days, and although websites selling NPS often offer expedited shipping (Meyers et al., 2015), a few days shift from purchase to delivery can still be expected, as well as a shift from delivery to intoxication. This finding may still support the possibility of same month co-occurrence of web search queries and toxicological admissions. Considering the contemporaneous correlation of GDS data identified with the reported monthly case numbers, one might justly argue whether these associations can easily be attributed to the phenomenon that news reports about the harms of certain NPS may evoke increases in web searches for the given drug (Forsyth, 2012), in this case, for GHB. In that sense, media reports could be interpreted as potential confounders when we focus on the association between GDS data and toxicological admission rates; however, this potential confounding effect does not seem to be powerful: when we pulled google searches prior in time, or made a multivariable analysis accounting for shifted google search terms, 
contemporaneous correlations and variables have lost their significance. Additionally, we have observed a decline in search volumes in late 2010. While we can (and should) only speculate the reasons behind it, this decline might be attributed to the fact that the legislative status of NPS-type drugs was changed around the end of 2010 and the very beginning of 2011 in Hungary, leading to reduced web interest towards specific NPS (e.g., KapitányFövény \& Demetrovics, 2017).

Consistent with comparable findings describing seasonal patterns in the variability of psychoactive substance intoxications mainly related to public holidays or social events (e.g., Lloyd et al., 2013), we also identified two seasonal peaks (December/January and May) in GHB-intoxication-related admission rates. Just like as it is reported in the case of alcohol intoxications (e.g., Kushnir \& Cunningham, 2014), GHB-related hospital admissions peaked around Christmas and New Year's Eve, whereas May's peak might be linked to the celebration of Labor's Day (1st of May) or Whitsun, although these are only presumptions not necessarily confirmed by our data. Similar to the results of Madah-Amiri et al. (2017), a weekend pattern of increased GHB poisoning frequencies was observed within the confines of the present study. These findings therefore suggest a seasonal trend and a more significant weekly temporal one in case of GHB intoxications, although due to the small sample size of this study, we cannot generalize this assumption. The trend of weekends' elevated GHB use frequencies can most possibly be linked to GHB's high reputation among club goers who mainly consume this drug within recreational settings (e.g., rave parties) (Kapoor et al., 2013). It also needs to be stated that GHB is sometimes used in sexual assaults as a roofie, detected in approximately $0.2-4.4 \%$ of reported sexual offenses (Németh et al., 2010), that contributes to complicating the picture of GHB intoxications and may undermine the interpretation of any identified trends.

\section{Limitations and Future Research}

Our study is not without limitations of which most are derived from the nature of the study, including the disadvantages of secondary data analysis, such as the possibility of residual confounding due to unmeasured variables associated with either the covariates or the outcome of interest. In addition, seasonality was not involved in our model. As it is often observed during the analysis and interpretation of online activity-based data and the secondary analysis of routinely collected clinical data, main risks of bias include the fact that routine data collection differs from data collected directly for the purpose of specific research which is essential for valid hypothesis testing. As such we cannot fully rely on the empirical findings of our similar studies (e.g., Martin-Sanchez et al., 2017). An important methodological question also arises from the results of the present study: how can we improve the generalizability of the findings of similar research aiming to use web search query rates in predicting toxicologic admission rates? In order to provide an empirically supported answer to that question, ideally an external validation approach should be followed, for instance, by applying the model on prospectively collected data. With a recruitment of patients admitted to toxicology wards due to GHB intoxication, it would be feasible to directly explore these patients' main sources of GHB purchase and then describe the rate of online purchase within this sample (most favorably a randomly selected representative one). We selected only one treatment site as the source of the analyzed clinical data. And even though the Clinical Toxicology Ward of Péterfy Sándor Street Hospital Clinic and Casualty Centre is characterized by the highest admission rates with cases coming not only from the capital but from rural areas as well, this selection may still affect our results. 
In case of our search term "Gina drog," we added the term "drog" in order to increase the specificity of the assessed search queries as Gina itself is a female name. However, those who use GHB usually refer to this drug simply as Gina. This might explain the fact that Gina-related search results - as compared to GHB-related ones-showed limited association with toxicological admission rates. Finally, we repeatedly use the term prediction throughout our analyses; however, based on the applied methodology, we might only talk about correlations.

\section{Conclusions}

Our study demonstrated the potential of web search volumes in the prediction of monthly toxicologic admissions related to GHB intoxications and highlighted the scope of this modeling method in toxicology. On the other hand, a considerable number of limitations may reduce the generalizability of our results. This study is therefore considered as a first step to provide empirical basis for future studies, aiming to explore the predictive potential of web search metrics in the field of toxicology.

Acknowledgements Máté Kapitány-Fövény acknowledges the support by the János Bolyai Research Scholarship of the Hungarian Academy of Sciences and the support by the ÚNKP-20-5 New National Excellence Program of the Hungarian Ministry for Innovation and Technology.

Funding Open access funding provided by Semmelweis University. This study was supported by the Hungarian National Research, Development and Innovation Office (Grant numbers: KKP126835, NKFIH-1157-8/2019-DT).

Data Availability Analyzed dataset is available at https://github.com/msulyok/GHBGoogleTrends.

\section{Declarations}

Conflict of Interest The authors declare no competing interests.

Open Access This article is licensed under a Creative Commons Attribution 4.0 International License, which permits use, sharing, adaptation, distribution and reproduction in any medium or format, as long as you give appropriate credit to the original author(s) and the source, provide a link to the Creative Commons licence, and indicate if changes were made. The images or other third party material in this article are included in the article's Creative Commons licence, unless indicated otherwise in a credit line to the material. If material is not included in the article's Creative Commons licence and your intended use is not permitted by statutory regulation or exceeds the permitted use, you will need to obtain permission directly from the copyright holder. To view a copy of this licence, visit http://creativecommons.org/licenses/by/4.0/.

\section{References}

Aldridge, J., Stevens, A., \& Barratt, M. J. (2018). Will growth in cryptomarket drug buying increase the harms of illicit drugs? Addiction (abingdon, England), 113(5), 789-796.

Barker, J. C., Harris, S. L., \& Dyer, J. E. (2007). Experiences of gamma hydroxybutyrate (GHB) ingestion: A focus group study. Journal of Psychoactive Drugs, 39(2), 115-129.

Batistic, F. K., Rhumorbarbe, D., Lefrancois, E., Tettey, J., Raithelhuber, M., Rossy, Q., \& Morelato, M. (2021). Analysis of Google Trends to monitor new psychoactive substance. Is there an added value? Forensic Science International, 326, 110918. https://doi.org/10.1016/j.forsciint.2021.110918 
Bright, S. J., Bishop, B., Kane, R., Marsh, A., \& Barratt, M. J. (2013). Kronic hysteria: Exploring the intersection between Australian synthetic cannabis legislation, the media, and drug-related harm. International Journal on Drug Policy, 24(3), 231-237.

Cavazos-Rehg, P. A., Krauss, M. J., Sowles, S. J., \& Bierut, L. J. (2016). Marijuana-related posts on Instagram. Prevention Science: The Official Journal of the Society for Prevention Research, 17(6), 710-720.

Couper, F. J., Thatcher, J. E., \& Logan, B. K. (2004). Suspected GHB overdoses in the emergency department. Journal of Analytical Toxicology, 28(6), 481-484.

Elekes, Zs. (2012). ESPAD 2011 (Európai Iskolavizsgálat a fiatalok alkohol- és egyéb drogfogyasztási szokásairól) ötödik hullámának magyarországi adatfelvétele. [ESPAD 2011 - Fifth wave of the European School Survey Project on Alcohol and other Drugs]. Munkabeszámoló. OTKA. Available at: https://real.mtak.hu/12613/1/81353_ZJ1.pdf. Accessed 18 March 2021

Fincham, J. E. (2021). Negative consequences of the widespread and inappropriate easy access to purchasing prescription medications on the internet. American Health \& Drug Benefits, 14(1), 22-28.

Forsyth, A. J. M. (2012). Virtually a drug scare: Mephedrone and the impact of the Internet on drug news transmission. International Journal of Drug Policy, 23, 198-209.

Fox, J., \& Weisberg, S. (2018). Appendix: Nonparametric regression in $R$. An $R$ companion to applied regression (3rd ed.). SAGE Publishing. ISBN 978-1-5443-3645-9.

Gamma, A., Schleifer, R., Weinmann, W., Buadze, A., \& Liebrenz, M. (2016). Could Google trends be used to predict methamphetamine-related crime? An analysis of search volume data in Switzerland, Germany, and Austria. PLoS ONE, 11(11), e0166566. https://doi.org/10.1371/journal.pone.0166566

Ghosh, A., Bisaga, A., Kaur, S., \& Mahintamani, T. (2021). Google Trends data: A potential new tool for monitoring the opioid crisis. European Addiction Research, 15, 1-8.

Hammoud, M. A., Bourne, A., Maher, L., Jin, F., Haire, B., Lea, T., Degenhardt, L., Grierson, J., \& Prestage, G. (2018). Intensive sex partying with gamma-hydroxybutyrate: Factors associated with using gamma-hydroxybutyrate for chemsex among Australian gay and bisexual men - results from the Flux Study. Sexual Health, 15(2), 123-134.

Kalyanam, J., Katsuki, T., Lanckriet, G. R. G., \& Mackey, T. K. (2017). Exploring trends of nonmedical use of prescription drugs and polydrug abuse in the Twittersphere using unsupervised machine learning. Addictive Behaviors, 65, 289-295.

Kapitány-Fövény, M., \& Demetrovics, Z. (2017). Utility of Web search query data in testing theoretical assumptions about mephedrone. Human Psychopharmacology, 32(3), 1-7. https://doi.org/10.1002/ hup. 2620

Kapitány-Fövény, M., Zacher, G., Posta, J., \& Demetrovics, Z. (2017). GHB-involved crimes among intoxicated patients. Forensic Science International, 275, 23-29.

Kapoor, P., Deshmukh, R., \& Kukreja, I. (2013). GHB acid: A rage or reprive. Journal of Advanced Pharmaceutical Technology \& Research, 4(4), 173-178.

Kushnir, V., \& Cunningham, J. A. (2014). Event-specific drinking in the general population. Journal of Studies on Alcohol and Drugs, 75(6), 968-972.

Lloyd, B., Matthews, S., Livingston, M., Jayasekara, H., \& Smith, K. (2013). Alcohol intoxication in the context of major public holidays, sporting and social events: A time-series analysis in Melbourne, Australia, 2000-2009. Addiction, 108(4), 701-709.

Mackey, T. K., \& Nayyar, G. (2016). Digital danger: A review of the global public health, patient safety and cybersecurity threats posed by illicit online pharmacies. British Medical Bulletin, 118(1), 110-126.

Madah-Amiri, D., Myrmel, L., \& Brattebø, G. (2017). Intoxication with GHB/GBL: Characteristics and trends from ambulance-attended overdoses. Scandinavian Journal of Trauma, Resuscitation and Emergency Medicine, 25(1), 98. https://doi.org/10.1186/s13049-017-0441-6

Mainous, A. G., 3rd., Everett, C. J., Post, R. E., Diaz, V. A., \& Hueston, W. J. (2009). Availability of antibiotics for purchase without a prescription on the internet. Annals of Family Medicine, 7(5), 431-435.

Martin-Sanchez, F. J., Aguiar-Pulido, V., Lopez-Campos, G. H., Peek, N., \& Sacchi, L. (2017). Secondary use and analysis of big data collected for patient care. Yearbook of Medical Informatics, 26(1), 28-37.

Meyers, K., Kaynak, Ö., Bresani, E., Curtis, B., McNamara, A., Brownfield, K., \& Kirby, K. C. (2015). The availability and depiction of synthetic cathinones (bath salts) on the Internet: Do online suppliers employ features to maximize purchases? The International Journal on Drug Policy, 26(7), 670-674.

Miliano, C., Margiani, G., Fattore, L., \& De Luca, M. A. (2018). Sales and advertising channels of new psychoactive substances (NPS): Internet, social networks, and smartphone apps. Brain Sciences, 8(7), 123. https://doi.org/10.3390/brainsci8070123

Németh, Z., Kun, B., \& Demetrovics, Z. (2010). The involvement of gamma-hydroxybutyrate in reported sexual assaults: A systematic review. Journal of Psychopharmacology, 24(9), 1281-1287. 
Nuti, S. V., Wayda, B., Ranasinghe, I., Wang, S., Dreyer, R. P., Chen, S. I., \& Murugiah, K. (2014). The use of google trends in health care research: A systematic review. PLoS ONE, 9(10), e109583. https://doi. org/10.1371/journal.pone.0109583

Orsolini, L., Papanti, G. D., Francesconi, G., \& Schifano, F. (2015). Mind navigators of chemicals' experimenters? A web-based description of e-psychonauts. Cyberpsychology, Behavior, and Social Networking, 18(5), 296-300.

Országos Kémiai Biztonsági Intézet. (2012). Jelentés az országos emberi mérgezési esetekról - 2011. Egészségügyi Toxikológiai Tájékoztató Szolgálat.

Országos Kémiai Biztonsági Intézet. (2014). Jelentés az országos emberi mérgezési esetekról - 2013. Egészségügyi Toxikológiai Tájékoztató Szolgálat.

Paksi, B., Demetrovics, Z., Magi, A., \& Felvinczi, K. (2018). A magyarországi felnőtt népesség droghasználata - az országos lakossági adatfelvétel az addiktológiai problémákról 2015 (OLAAP 2015) reprezentatív lakossági felmérés alapján. Magyar Pszichológiai Szemle, 73(4), 541-565.

Perdue, R. T., Hawdon, J., \& Thames, K. M. (2018). Can big data predict the rise of novel drug abuse? Journal of Drug Issues, 48(4), 508-518.

R Core Team. (2020). R: A language and environment for statistical computing. R Foundation for Statistical Computing.

Smith, S. W., \& Garlich, F. M. (2013). Availability and supply of novel psychoactive substances. In P. I. Dargan \& D. M. Wood (Eds.), Novel psychoactive substances: Classification, pharmacology and toxicology (pp. 55-86). Academic Press.

Stein, L. A., Lebeau, R., Clair, M., Martin, R., Bryant, M., Storti, S., \& Monti, P. (2011). A web-based study of gamma hydroxybutyrate (GHB): Patterns, experiences, and functions of use. The American Journal on Addictions, 20(1), 30-39.

Steppan, M., Kraus, L., Piontek, D., \& Siciliano, V. (2013). Are cannabis prevalence estimates comparable across countries and regions? A cross-cultural validation using search engine query data. The International Journal on Drug Policy, 24(1), 23-29.

Van Hout, M. C., \& Hearne, E. (2017). New psychoactive substances (NPS) on cryptomarket fora: An exploratory study of characteristics of forum activity between NPS buyers and vendors. The International Journal on Drug Policy, 40, 102-110.

Yin, S., \& Ho, M. (2012). Monitoring a toxicological outbreak using Internet search query data. Clinical Toxicology (philadelphia, Pa), 50(9), 818-822.

Publisher's Note Springer Nature remains neutral with regard to jurisdictional claims in published maps and institutional affiliations. 